ISSN 1112-9867

http://www.jfas.info

\title{
EXPERIMENTAL INVESTIGATION OF INDUSTRIAL COPPER DEFORMED BY WIRE DRAWING PROCESS
}

\author{
L. Fellah ${ }^{1, *}$, Z. Boumerzoug ${ }^{2}$ \\ ${ }^{1}$ Faculty of Hydrocarbons and Renewable Energies and Earth and Universe Sciences, \\ University of Kasdi Merbah, Ouargla, Algeria \\ ${ }^{2}$ Laboratory of Semiconductors and Metallic Materials(LSMM), University of Mohamed \\ Khider, Biskra, Algeria
}

Received: 20 April 2017 / Accepted: 22 November 2017 / Published online: 01 January 2018

\begin{abstract}
The scope of this work is to investigate the effect of the cold deformation by wire-drawing on microstructure and physical properties of industrial copper wires. Copper wires were provided by E.N.I.CA.Biskra (Algeria). We investigated some wires with different strain levels (as received, $1.20,2.10$, and $\varepsilon=3.35)$. X-ray diffraction, optical microscopy, and electrical resistivity measurement have been used as characterization techniques. We analyzed the photographs using "ImageJ" software and DRX patterns using PM2K software. The results revealed that the cold wire-drawing causes a lengthening of grains along the axis of wire-drawing, and introduced large amounts of defects. The results also showed, on the one hand, the decrease in crystallite size, lattice parameter, and the outer cut-off radius, on the other hand, the increase of the electrical resistivity and the dislocation density in the copper wires.
\end{abstract}

Keywords: Industrial copper; deformation; Dislocations; Shape factor; X-ray diffraction.

Author Correspondence, e-mail: fellahcene@yahoo.fr

doi: http://dx.doi.org/10.4314/jfas.v10i1.7 


\section{INTRODUCTION}

Wire-drawing is a technique for cold forming of metals and metal alloys, which reduces the area cross-section of a wire by pulling it through a series of dies. Using of a lubricant reduces the phenomenon of warming and prevents scratching of the outer surface of the wire [1]. There is a large field of use of drawn copper wires such as the manufacture of cables for the transport of electric power, coils, and wires for the building electricity.

Wire-drawing is habitually performed at room temperature so called cold wire-drawing; however, it can be performed at high temperature for large reduction ratio [2]. Wire-drawing causes hardening of the metal wires and degradation of their mechanical and electrical properties. These degradations are due to the various microstructural defects introduced by this plastic deformation, in particular by increasing the density of the defects (e.g. dislocations and faulting). When the strain degree of cold wire-drawing becomes very important the microstructure will present a morphological texture. The grains become long and shaped like needles parallel to the wiredrawing direction $[3,4]$.

In present investigation, we focused on the evolution of the microstructure of copper wires drawn at different deformation levels using, on the one hand, conventional metallographic methods such as optical microscopy and on the other hand the recently proposed numerical fitting procedure, the Whole Powder Pattern Modeling (WPPM) [5, 6]. The diffractograms were refined using the PM2K software [7, 8].

\section{EXPERIMENTAL PROCEDURES}

\subsection{Material Studied}

The material studied in this study is an industrial copper used in manufacture of electric wiring and cables by the national company E.N.I.CA.Biskra.

Table 1 shows the content of the copper studied in various impurities. Wire-drawing process was carried out for the wires with initial diameter of $8 \mathrm{~mm}$ to the final diameter of $1.50 \mathrm{~mm}$ in four draws using industrial conical dies. During the deformation process, the Tungsten carbide dies were constantly lubricated with a mixture of oils. Nomenclature of samples and deformation levels are listed in Table 2. 
The strain values are calculated using the following relation $[9,10]$ :

$\varepsilon=2 \cdot \ln \frac{r_{i}}{r_{f}}$

Where $r_{i}$ and $r_{f}$ are the initial and the final radius of the copper wire respectively.

Table 1. Impurities ratio (ppm) in the copper used in this work

\begin{tabular}{ccccccccccc}
\hline $\mathbf{C u}$ & $\mathbf{A g}$ & $\mathbf{B i}$ & $\mathbf{S b}$ & $\mathbf{A s}$ & $\mathbf{F e}$ & $\mathbf{N i}$ & $\mathbf{P b}$ & $\mathbf{S n}$ & $\mathbf{S}$ & $\mathbf{Z n}$ \\
\hline 99.966 & 10 & 1 & 2 & 2 & 5 & 2 & 5 & 2 & 4 & 1 \\
\hline
\end{tabular}

Table 2. Strain values of the copper wires used in this work.

\begin{tabular}{cccccc}
\hline Sample & A & B & C & D & E \\
\hline $\boldsymbol{\varepsilon}$ & As-received & 1.20 & 2.10 & 2.45 & 3.35 \\
\hline
\end{tabular}

\subsection{XRD Data Collecting}

The diffractograms were carried out from flat polished surfaces of samples by X'Pert-Pro MRD Philips X-ray diffractometer with a Bragg-Brentano configuration, and operating at 40 $\mathrm{kV}$ et $40 \mathrm{~mA}$, using a copper anticathod delivering a $C u_{K \alpha}$ radiation $\left(\lambda_{\alpha 1}=1.5406 \AA\right)$. The Bragg angle $2 \theta$ was varied from $2 \theta_{i}=40^{\circ}$ to $2 \theta_{f}=100^{\circ}$. The step of the continuous scan was $\Delta \theta=0.017^{\circ}$ and the counting time was $5.08 \mathrm{~s} / \mathrm{step}$.

\subsection{Material Preparation}

A metallographic diamond-cutting saw was used to cut the samples. The surfaces of samples were polished using an abrasive silicon carbide paper of different granularity. The polished surfaces were finished using diamond paste spread out on a felt fabric. A chemical etchant with the composition of $40 \mathrm{~mL}\left(\mathrm{HNO}_{3}\right.$ concentrated to $\left.55 \%\right)$ and $10 \mathrm{~mL}\left(\mathrm{H}_{2} \mathrm{O}\right)$ was used to reveal the microstructure. The microstructure analyses were performed by an optical microscope (Hund-T100/Wetzlar, Germany) equipped with a camera Canon (Canon Inc. Japan). The analysis of micrographs was performed using software called "ImageJ". It is an open source software image processing designed for scientific images [11].

\subsection{Electrical Resistivity Measurement}

The measurements of the electrical resistivity were carried out at $293 \mathrm{~K}$, on samples of 1.20 
$\mathrm{m}$ length taken directly on the factory production line. "Resistotmat bridge-type 3202" apparatus has been used which allows good precision.

\section{ANALYTICAL PROCEDURES}

\subsection{Whole Powder Pattern Modeling Refinement}

The algorithm of Whole Powder Pattern Modeling (WPPM) were used to refine DRX diffractograms to determine the physic parameters of microstructure such as lattice parameter (a), defect densities (dislocations $d_{d i s}$ and stacking faults probability $\alpha$ ), crystallite size distribution, and the size of coherent diffraction domains.

In this model of Line Profile Analysis method (LPA), the whole measured diffraction pattern is fitted directly by the sum of the background and the theoretically constructed profile functions based on Physic Models. These functions are computed for each Bragg-reflection as a convolution of the inverse Fourier transforms of the theoretically well-established size and strain Fourier coefficients and the measured instrumental profiles [5, 6, 12-14].

In the calculations, the domains are assumed to have a spherical shape and their size being the diameter of a sphere.

The crystallite size is given by Eq. 2, and the distribution function is defined by a lognormal model as expressed in Eq. 3 [5, 6, and 15].

$$
\begin{aligned}
& \langle\mathrm{D}\rangle=\exp \left(\mu+\frac{\sigma^{2}}{2}\right) . \\
& \mathrm{g}(\mathrm{D})=\frac{1}{\mathrm{D} \cdot \sigma \cdot \sqrt{2 \pi}} \cdot \exp \left[-\frac{1}{2} \frac{(\ln \mathrm{D}-\mu)^{2}}{\sigma^{2}}\right] .
\end{aligned}
$$

Where: $\sigma, \mu$, and $<D>$ are the lognormal variance, lognormal mean and the mean size distribution, respectively.

\subsection{Light Microscopy Images Analysis}

In metallography, we can analyze quantitatively the micrographs by describing the shape of objects (e.g. grains, pearlite lamellae). To describe the shape of the object quantitatively, one usually uses some parameters called "shape descriptors". The calculation of the shape descriptors is based on measurements carried out directly on a micrograph such as the length, 
area, perimeter, and coordinates of mass-center [16].

There are several rules and techniques for the calculation of shape descriptors. One of which assigns the object a standard geometry (e.g. circle). The shape factor SF (so called circularity factor) is one of the shape descriptors. It calculates how circular an object is. A perfect circle has a shape factor of $\mathrm{SF}=1$, and a line has a shape factor approaching $\mathrm{SF}=0$ (given by Eq. 4).

Diameter of Feret $L_{\max }$ (Eq. 5) measures the greatest distance between two arbitrary points on a grain boundary. The parameter AR expresses the aspect ratio of an ellipse fitted to the shape of a particle or grain microstructure, its value is the ratio of the major axis to the minor axis of this ellipse fictitious (Eq. 6), and the roundness Rnd is the inverse of Aspect Ratio [17].

$$
\begin{aligned}
& S F=4 \pi \frac{\text { area }}{\text { perimeter }^{2}} . \\
& \mathrm{L}_{\max }=\sqrt{4 \frac{\text { area }}{\pi}} . \\
& \mathrm{AR}=\frac{\mid \text { Major axis } \mid}{\mid \text { Minor axis } \mid} .
\end{aligned}
$$

\section{RESULTS AND DISCUSSION}

\subsection{XRD Line Profile Analysis}

Fig. 1 shows a graphical output of WPPM for typical X-ray diffractogram of the as-received wire rod (A). The full width at half maximum (FWHM) is smaller before wire-drawing. As it has been noticed in another research works, the effect of cold working is not yet discernible, which is evident from the widths of the peaks $[18,19]$.

Fig. 2 shows the effect of cold wire-drawing on the shape and position of (111) diffraction peaks. We have observed a shifting and broadening of peaks, which indicates clearly that the microstructural features of drawn wires were affected by the cold deformation. These effects are probably due to the reduction of the size of the crystallites, distortion of the crystal lattice, and the increase of defects in the deformed wires such as dislocation and stacking fault densities. 


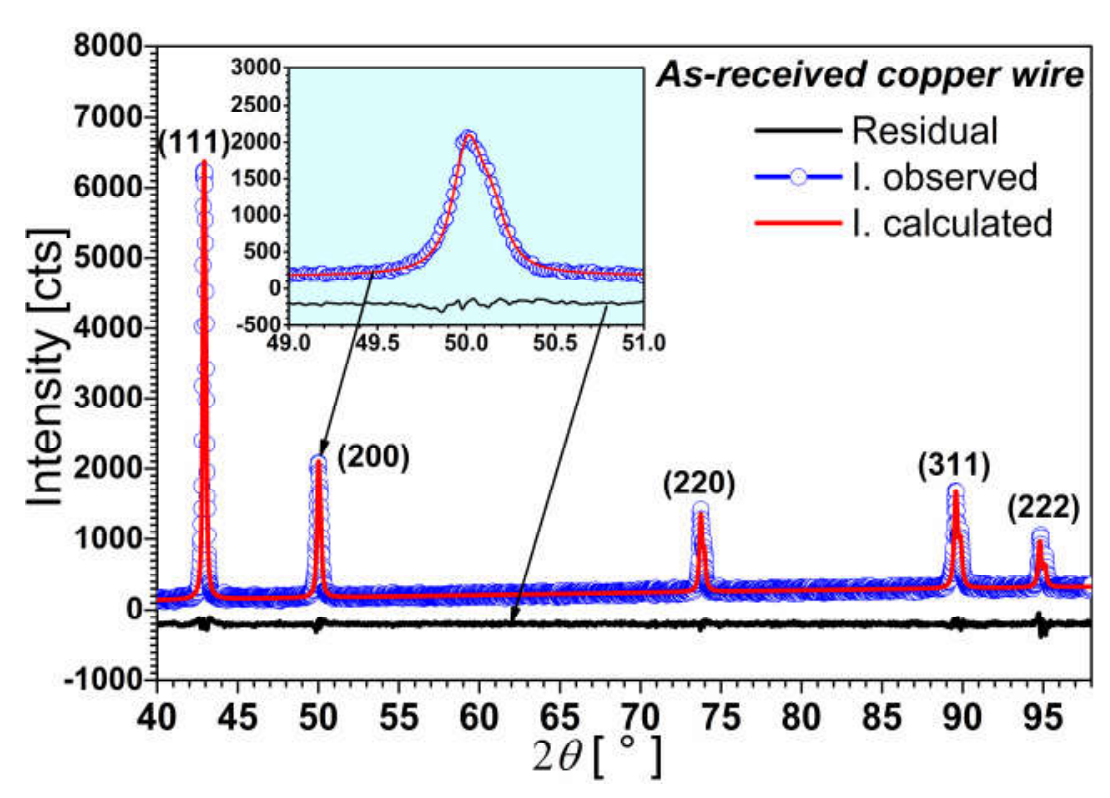

Fig.1. X-ray diffractogram of the as-received wire refined by WPPM procedure.

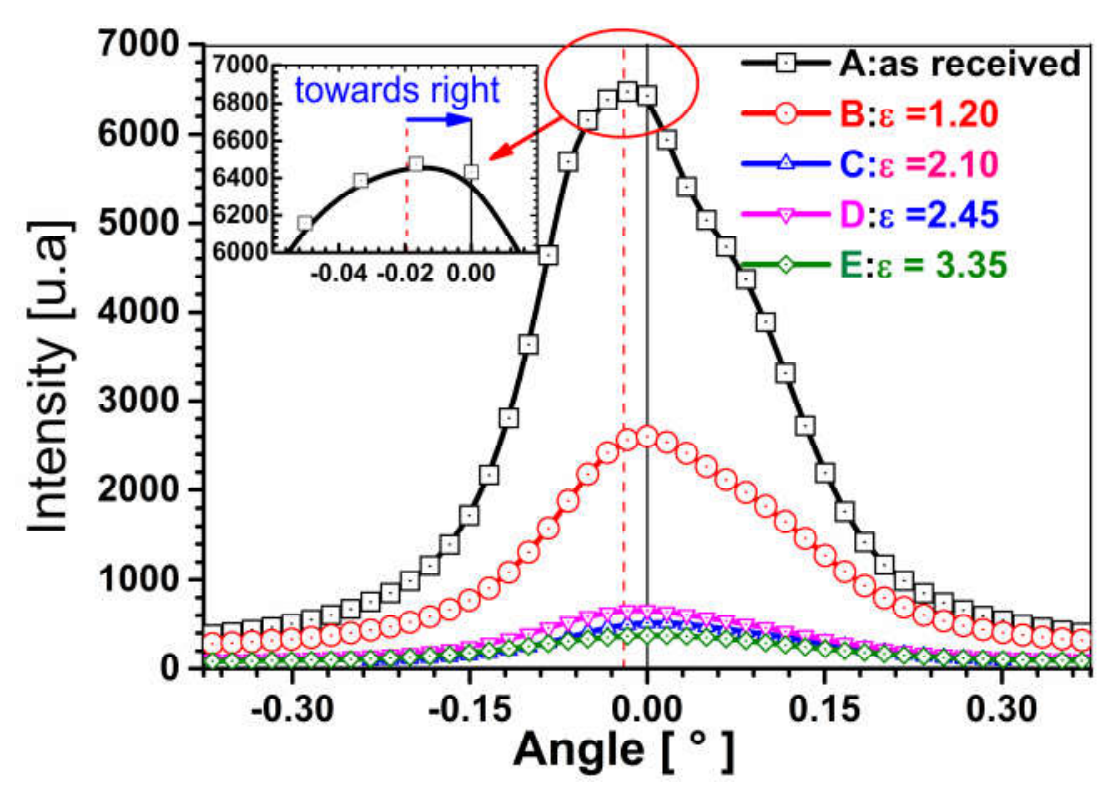

Fig.2. Peak profiles (111) corresponding to each reduction area of the cross-section.

Fig. 3 presents the results of WPPM refinement for the copper wires deformed at 1.20 (Fig.3a), 2.10 (Fig.3b), 2.45 (Fig.3c), and $\varepsilon=3.35$ (Fig.3d) strain levels respectively. Experimental data (blue circles) are reported together with the modeled data (red line) and the residual (black line below). The agreement between the experimental and modeled patterns, as shown by the residual (the difference between the experimental and modeled data), is quite satisfactory. The refinement parameters obtained by the WPPM procedure are given in Table 3. 
Cold drawing process causes the shifting (to right side) and broadening of the diffraction peaks. The profile broadening results of several contributions including the crystallite size effect, the effect of linear and planar defects, and the instrumental contribution (diffractometer). The observed experimental facts indicate that the microstructural parameters of deformed samples were affected. We noted on the one hand the decrease of the lattice parameter, of the amplitude of the outer cut-off radius, as well as the average size of the crystallites; and on the other hand, we found that the dislocation density increases. The increase of dislocation density $d_{d i s}$ is explained by work hardening mechanism upon cold drawing by continued trapping of newly created mobile dislocations, existing dislocations and their incorporation into the various microstructural elements [20].
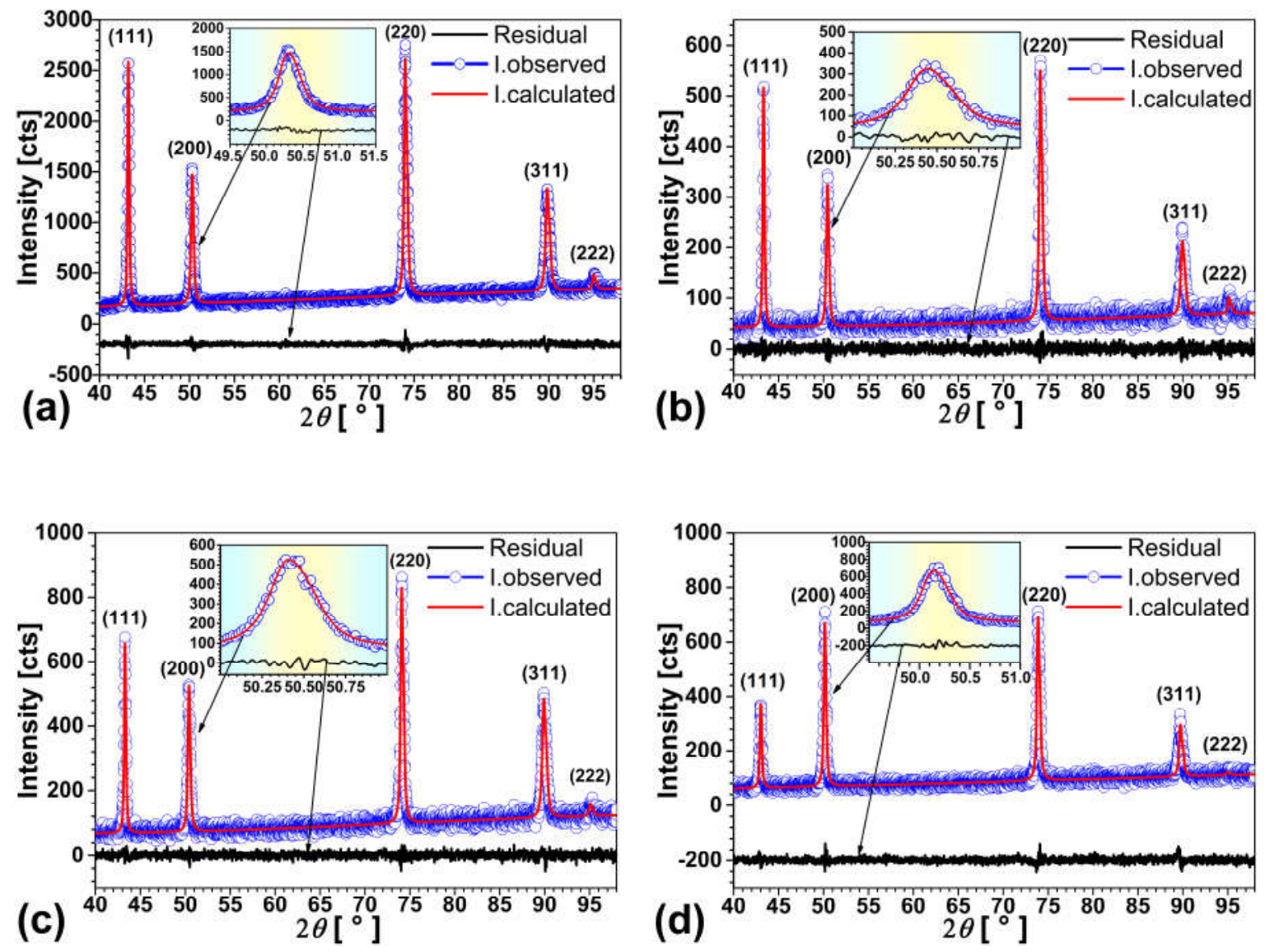

Fig.3. X-ray diffractograms refined by WPPM procedure of wires drawn at:

a) $\varepsilon=1.20$, b) $\varepsilon=2.10$, c) $\varepsilon=2.45$, and d) $\varepsilon=3.35$. 
Table 3. Summary of agreement parameters obtained by WPPM refinement

\begin{tabular}{cccccc}
\hline Sample & Strain $\boldsymbol{\varepsilon}$ & Rwp [\%] & Rexp [\%] & WSS & Gof (S) \\
\hline A & as-received & 7.5477 & 6.6836 & 6081.45 & 1.12854 \\
B & 1.20 & 5.7034 & 6.1008 & 4168.80 & 0.93486 \\
C & 2.10 & 9.7010 & 10.4549 & 4106.05 & 0.92790 \\
D & 2.45 & 10.2416 & 11.0658 & 4088.49 & 0.92552 \\
E & 3.35 & 10.8190 & 11.6406 & 4121.34 & 0.92943 \\
\hline
\end{tabular}

Fig. 4 shows the crystallite size distribution function $g(D)$ corresponding to the calculated lognormal mean $\mu$ and variance $\sigma$ values by using PM2k software. It can be observed that the median, $\mu$, and the variance, $\sigma$, of the size distributions decrease with the increase of the strain level. We noted the decrease of the size of coherent diffraction domains (crystallites) with the strain level. It is known that for metallic materials the size of crystallites decreases with increasing deformation level, while an annealing treatment tends to increase it by restoration (recovery and recrystallization) mechanism on the contrary [20-22].

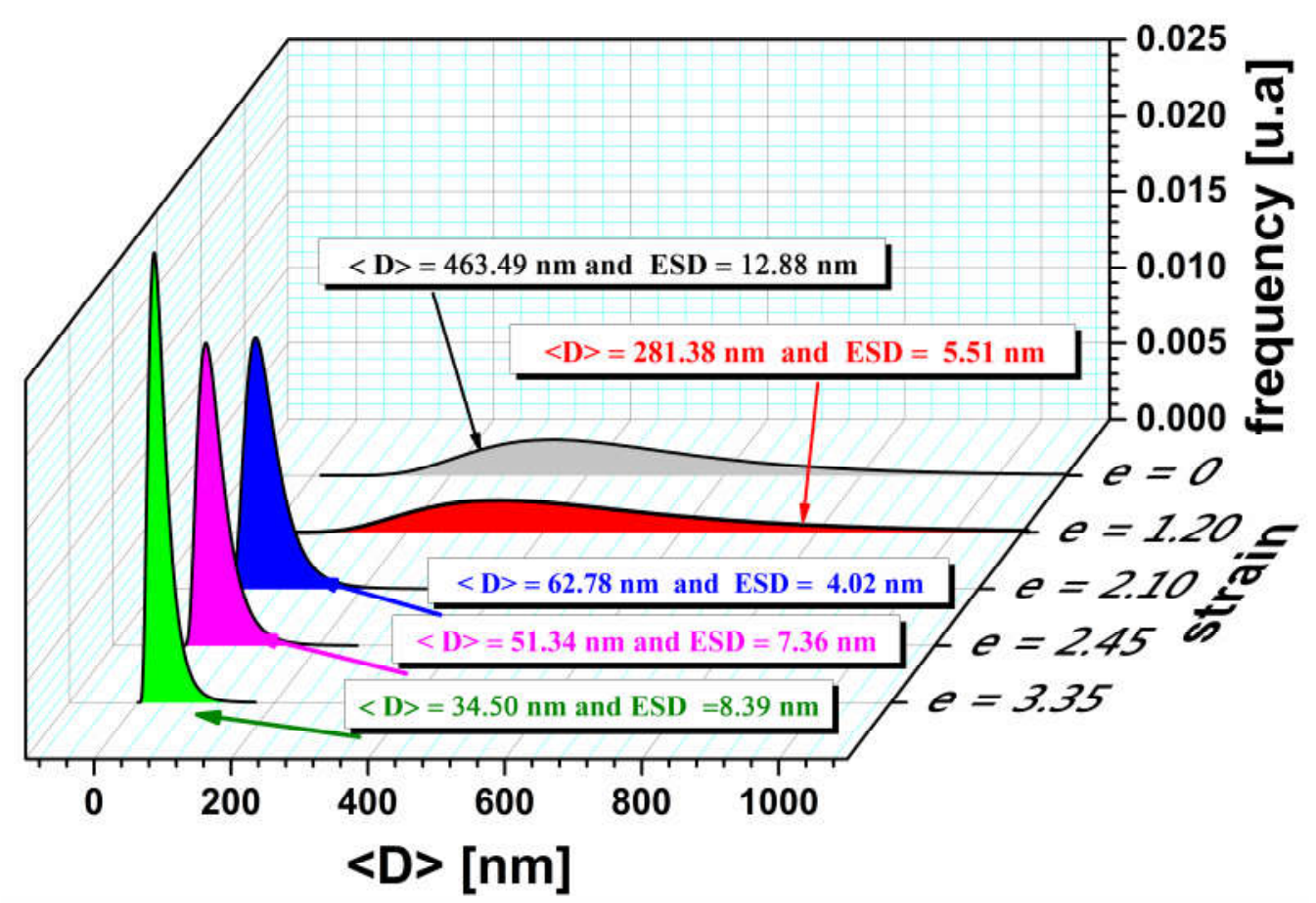

Fig.4. Distribution functions of the crystallite size of the as-received wire, and the wires drawn at different levels of deformation. 
The net probability of stacking faults is in range of $1.92 \times 10^{-3} \sim 4.95 \times 10^{-3}$; these values indicate the probable existence of planar defects related to the stack so called "stacking faults".

The outer cut-off radius $R_{e}$ is related dislocation density $d_{d i s}$ according to the relationship ( $M=R_{e} \cdot \sqrt{d_{d i s}}$ ), by means of Wilkens parameter (so called arrangement parameter); the average distance $l_{\text {dis }}$ between dislocations is defined as the inverse of the square root of the dislocation density, it is given by the expression: $l_{d i s .}=d_{d i s .}^{-1 / 2}[5,23-26]$. The refined parameters are presented in Table 4. For the most deformed state, the value of $M$ (arrangement parameter) becomes less than unity, which suggests that a strong screening dislocation stress fields and strong dislocation interactions characterize the configuration to a deformed material [27-30].

Table 4. Summary of microstructural parameters obtained by WPPM refinement

\begin{tabular}{cccccc}
\hline Sample & $\mathbf{A}$ & $\mathbf{B}$ & $\mathbf{C}$ & $\mathbf{D}$ & $\mathbf{E}$ \\
\hline Strain $\boldsymbol{\varepsilon}$ & as-received & $\mathbf{1 . 2 0}$ & $\mathbf{2 . 1 0}$ & $\mathbf{2 . 4 5}$ & $\mathbf{3 . 3 5}$ \\
\hline $\mathrm{a}[\mathrm{nm}]$ & 0.361619 & 0.361534 & 0.361514 & 0.361522 & 0.361419 \\
$d_{\text {dis }} \times 10^{14}\left[\mathrm{~m}^{-2}\right]$ & 2.948 & 10.254 & 13.442 & 13.396 & 14.056 \\
$\operatorname{Re}[\mathrm{nm}]$ & 31.239 & 45.277 & 17.033 & 13.854 & 2.678 \\
$\mathrm{M}$ & 0.536 & 1.450 & 0.625 & 0.507 & 0.100 \\
$\mathrm{D}[\mathrm{nm}]$ & 463.49 & 281.38 & 62.78 & 51.34 & 34.50 \\
$\mu$ & 6.044 & 5.515 & 4.022 & 3.814 & 3.416 \\
$\alpha \times 10^{-3}$ & 4.68 & 4.95 & 2.67 & 1.92 & 2.12 \\
\hline
\end{tabular}

\subsection{Evolution of Microstructure of the Material During Cold Wire-drawing Processing}

Fig. 5 shows the microstructure of as-received copper wire. The grains have approximately equal dimensions in all directions (equiaxed grains). By analyzing the micrograph, we noted that the Feret's diameter $\left(\mathrm{L}_{\max }\right)$ was in a range $(23.39-59.87 \mu \mathrm{m})$ with an average of $33.98 \mu \mathrm{m}$ and the shape factor (SF) equal to 0.74 approximately. Finally, we noticed the presence of twins, which were formed during the manufacture of the copper rod. 


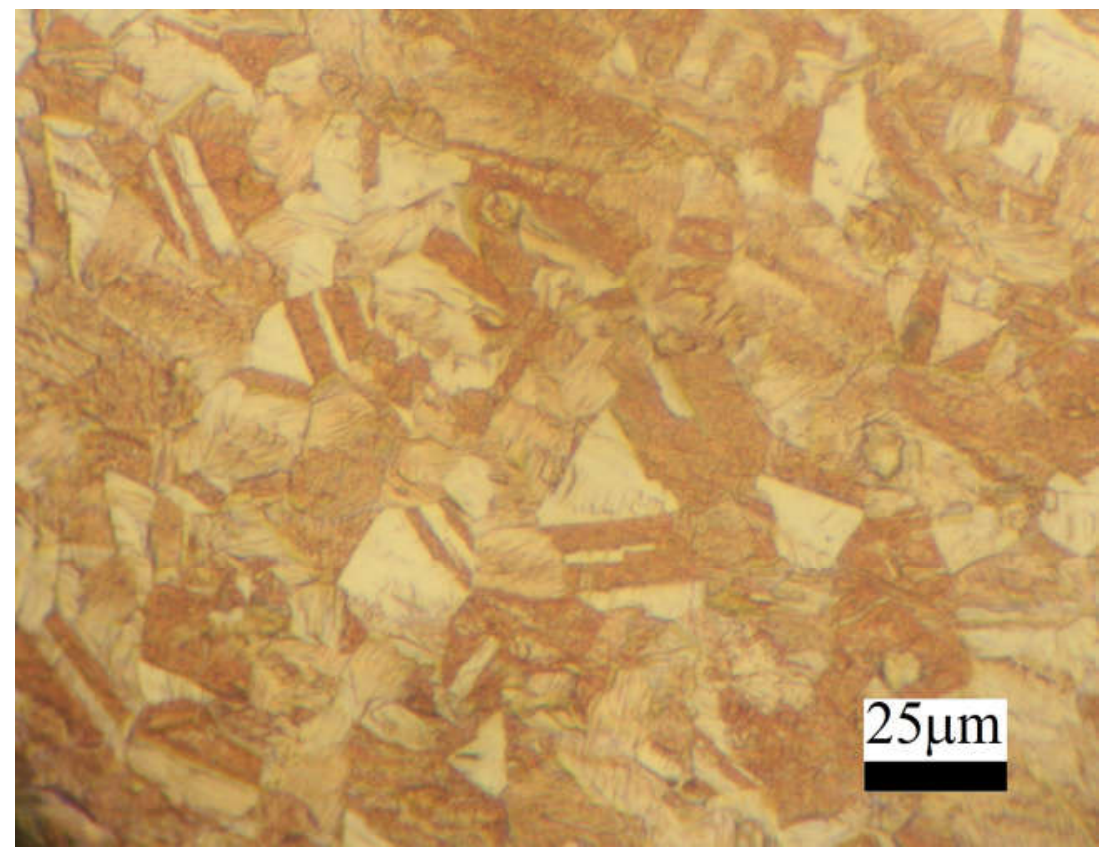

Fig.5. Microstructure of the as-received copper wire

Fig. 6 (a) shows elongated grains along the drawing axis for the copper wire drawn at $\varepsilon=1.20$, this elongation is becoming increasingly important, as and when the deformation is larger (Fig. 6-b, c, and d). The grains become longer and thinner. According to Fellah [31] and Baci et al. [32], when the degree of deformation increases, the drawn wire acquires a textured microstructure so-called "wire-drawing of texture" [33, 34]. This type of texture is usually encountered in the cold deformation of metallic materials and their alloys by "drawing" process. The axis of drawing (axis of the wire) constitutes the axis of symmetry for this kind of texture it is called "fiber axis" [35]. 

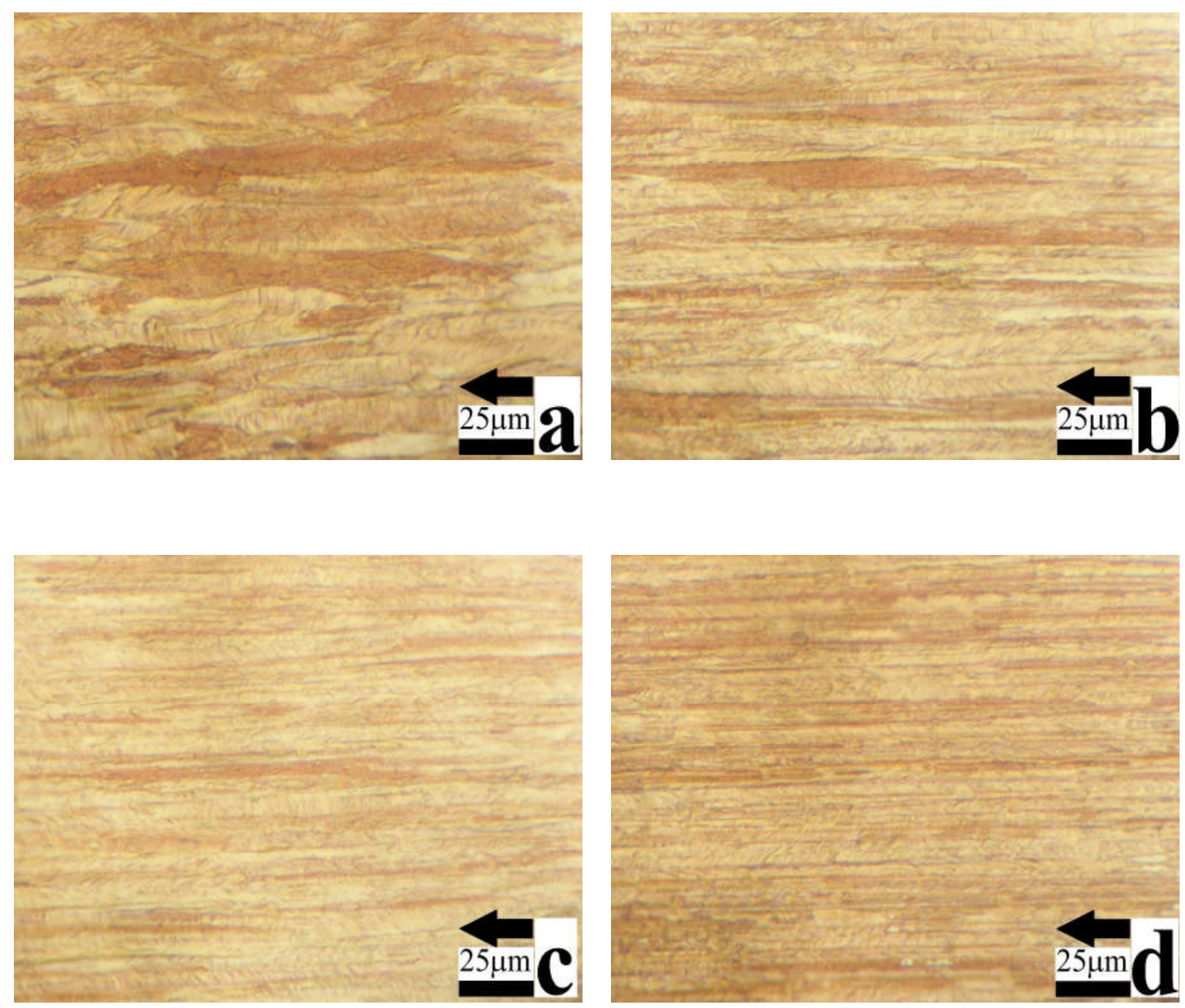

Fig.6. Microstructure of industrial copper wires after cold wire-drawing at different strain levels:(a) 1.20 , (b) 2.10 , (c) 2.45 , and (d) $\varepsilon=3.35$ (arrow indicates the drawing direction).

Table 5 groups the calculated values of the shape descriptors. These results confirm the observations made by optical microscopy. In fact, the values of the shape factor (SF) and roundness (Rnd) tend towards 0.11 and 0.04 respectively, which means that the grains become longer and finer as needles. Feret's diameter tends towards $171 \mu \mathrm{m}$, which means that the average length of a grain is close to $171 \mu \mathrm{m}$.

Table 5. Shape descriptors values obtained by "ImageJ" analysis

\begin{tabular}{cccccc}
\hline Sample & Strain \& & $\begin{array}{c}\text { Shape Factor } \\
\text { SF }\end{array}$ & $\begin{array}{c}\text { Feret's diameter } \\
\mathbf{L}_{\max }[\boldsymbol{\mu m}]\end{array}$ & $\begin{array}{c}\text { Aspect Ratio } \\
\text { AR }\end{array}$ & $\begin{array}{c}\text { Roundness } \\
\text { Rnd }\end{array}$ \\
\hline A & as-received & 0.74 & 33.98 & 1.43 & 0.71 \\
\hline B & $\mathbf{1 . 2 0}$ & 0.32 & 137.71 & 6.61 & 0.16 \\
\hline
\end{tabular}




\begin{tabular}{llllll}
\hline C & $\mathbf{2 . 1 0}$ & 0.20 & 137.13 & 12.10 & 0.09 \\
\hline $\mathbf{D}$ & $\mathbf{2 . 4 5}$ & 0.16 & 158.53 & 15.98 & 0.06 \\
\hline E & $\mathbf{3 . 3 5}$ & 0.11 & 170.96 & 24.41 & 0.04 \\
\hline
\end{tabular}

\subsection{Influence of Cold Deformation on the Electrical Resistivity of Copper Wires}

Fig. 7 shows the evolution of the electrical resistivity $\rho$ as function of strain $\varepsilon$; we found that the resistivity $\rho$ of copper drawn wires increases with area reduction of wires cross-section. In fact, the plastic deformation of copper wires by cold wire-drawing induces a various types of defects, such as twins, stacking faults, grain boundaries, dislocations, and vacancies. The occurrence of these imperfections generates a decrease in electrical conductivity of the material, and thereafter increasing its electrical resistivity.

According to Matthiessen's rule, the resistivity at given temperature is expressed by [36, 37]:

$\rho(T)=\rho_{i}(T)+\Delta \rho(T)$.

where $\rho_{i}(T)$ is the resistivity of pure metal and the term $\Delta \rho(T)$ denotes the contribution of the various defects.

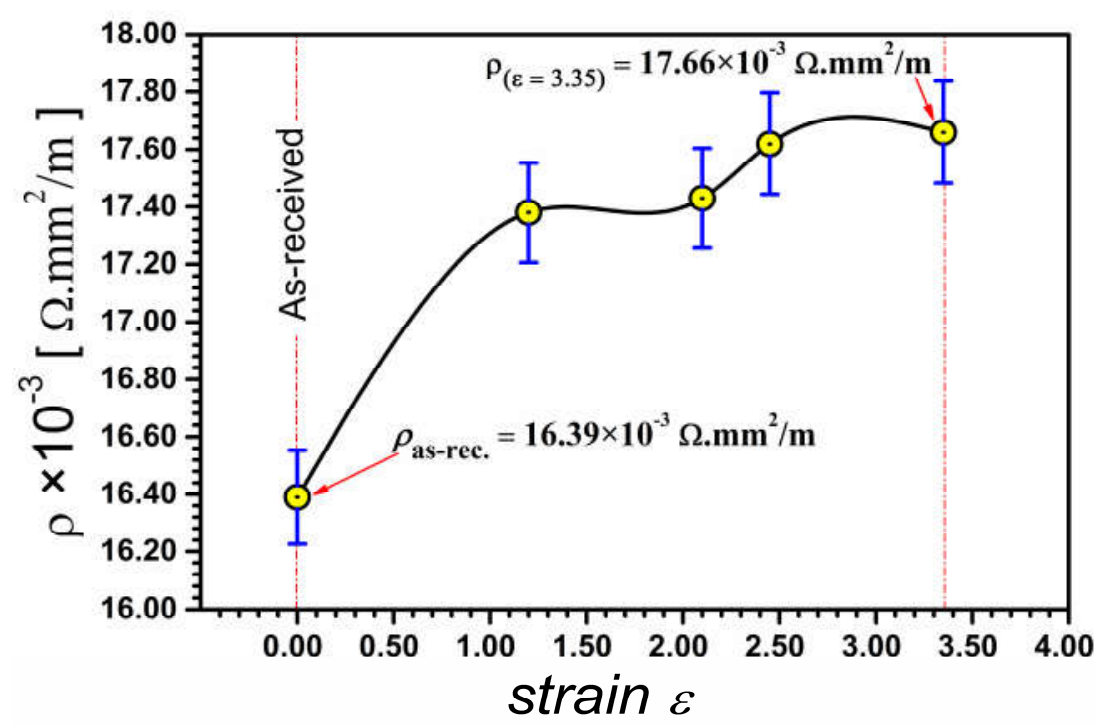

Fig.7. The electrical resistivity of drawn wires as a function of strain level.

\section{CONCLUSION}

This investigation represents a contribution to the study of the microstructure features evolution after deformation applied to industrial copper drawn wires, and its impact on the 
electrical resistivity. To summarize, the following conclusions can be made:

1. Cold wire-drawing caused crystallographic anisotropy, lengthening of grains along the axis of wire-drawing, and introduced large amounts of defects.

2. The dislocation density increased from $2.948 \times 10^{14}$ to $14.056 \times 10^{14} \mathrm{~m}^{-2}$.

3. Lattice parameter, size of the coherent diffraction domains and the outer cut-off radius decreased with the increase of strain level.

4. Values of shape descriptors changed indicating the grains tendency to become thinner and longer; indeed, the shape factor decreased from 0.74 to $\mathrm{SF}=0.11$ and the Feret's diameter increased towards $\sim 171 \mu \mathrm{m}$.

5. Values of the net probability of stacking faults indicated the probable existence of planar defects related to the stack so called "stacking faults".

6. The electrical resistivity increased from $16.39 \times 10^{-3}$ to $17.62 \times 10^{-3} \Omega . \mathrm{mm}^{2} / \mathrm{m}$ due to the increase of various defects.

\section{ACKNOWLEDGEMENTS}

Authors thank deeply, Prof. M. Leoni from Trento University (Italy), for assistance, help and for kindly providing the PM2k software.

Authors are grateful to the Industrial Cable Company of E.N.I.CA.Biskra (Algeria), for providing us copper wires, which allowed us to undertake this research.

\section{REFERENCES}

[1] Fellah L., Boumerzoug Z., Effect of wire-drawing on microstructural evolution of an industrial copper wire, $\mathrm{XI}^{\text {th }}$ International Conference «Prospects Of Fundamental Sciences Development», Tomsk, Russia, 2014, 293-241

[2] Paul DeGarmo E., Black J. T., Kohser R.A., Materials and Processes in Manufacturing. $9^{\text {th }}$ edn.: John Wiley, 2003,1168

[3] Jakani S., Effet des impuretés sur les mécanismes de recristallisation du cuivre tréfilé, $\mathrm{PhD}$, Université de Paris XI, Orsay, France : Paris, 2004

[4] Boumerzoug Z., Lahraki N., Zidani M., Mater Sci Forum, 2004,467-470,235-240, doi: 
10.4028/www.scientific.net/MSF.467-470.235

[5] Leoni M., Martinez-Garcia J., Scardi P., Mater Sci Forum. 2010, 651,173-186, doi: 10.4028/www.scientific.net/MSF.651.155

[6] Scardi P., Leoni M., Acta Cryst. Section A. 2002, 58(2), 190-200, doi:10.1107/S01087673 01021298

[7] Leoni M., Scardi P., PM2k software, Version 2.12, 2017, url:http://www.xrd.ing.unitn.it

[8] Leoni M., Confente T., Scardi P., Zeitschrift für Kristallographie, Supplement. 2006, 23(23), 249-254, doi: 10.1524/zksu.2006.suppl_23.249

[9] Haddi A., Imad A., Vega G., Tribol Trans. 2012, 55(4), 466-472, doi:10.1080/10402004. 2012.671451

[10] Fabík R., Halfarová P., Impact of drawing process parameters on uniformity of strain in spring wire. $20^{\text {th }}$ International Conference on Metallurgy and Materials, "Metal 2011" Conference proceedings: $2011 ; 234-240$

[11] ImageJ software open source,. Version1.51i, 2016, http://imagej.net/Downloads

[12] Scardi P., Leoni M., J Appl Cryst., 2006, 39(1), 24-31,doi:10.1107/S0021889805032978

[13] UngarT., Leoni M., Scardi P., J Appl Cryst. 1999, 32(2), 290-295, doi:10.1107/S002188 9898012710

[14] Scardi P., Leoni M., J Appl Cryst., 1999, 32(4), 671-682, doi:10.1107/S00218898990037 $4 \mathrm{X}$

[15] Leoni M., Martinez-Garcia J., Scardi P., J Appl Cryst., 2007, 40(4), 719-724, doi:10.11 07/S002188980702078X

[16] Wojnar L., Kurzydlowski K. J., Szala J., Praktyka analizy obrazu. edn. Kraków: Polskie Towarzystwo Stereologiczne, 2002,454

[17] Matusiewicz P., Czarski A., Adrian H., Metallurgy and foundry engineering. 2007, 33(1), 33-40, doi:10.7494/mafe.2007.33.1.33

[18] Boumerzoug Z., Lehraki N., Zidani M., Morphologie des grains d'un fil d'acier doux tréfilé à froid à l'entreprise TREFISOUD d'El-Eulma. Courrier du savoir. 2005,6 , 71-73 [19] Dey S.N., Chatterjee P., Gupta S.P.S., J Phys D: Appl Phys. 2005, 38(9), 1444-1449, doi: $10.1088 / 0022-3727 / 38 / 9 / 018$ 
[20] Shankaranarayan H., Varma S.K., J Mater Sci. 1995, 30(14), 3576-3586, doi:10.1007/ bf00351868

[21] Halder S.K., De M., Sen Gupta S.P., J Appl Phys. 1977, 48(8), 3560-3565, doi:10.1063/ 1.324155

[22] Ghosh S.K., Sen Gupta S.P., J Appl Phys. 1983, 54(11), 6652-6657, doi: $10.1063 / 1.331851$

[23] Scardi P., Leoni M., D’Incau M., Solid State Phenomena. 2007, 130, 27-32, doi: 10.4028/www.scientific.net/SSP.130.27

[24] Ungár T., Ribárik G., Zilahi G. et al., Acta Mater. 2014, 71(0), 264-282, doi:10.1016/ j.actamat.2014.03.024

[25] Wilkens M., phys stat sol (a). 1970, 2(2), 359-370, doi: 10.1002/pssa.19700020224

[26] Wilkens M., Acta Metallurgica. 1969, 17(9), 1155-1159, doi: 10.1016/0001-6160

(69)90092-3

[27] Groma I., Physical Review B. 1998, 57(13), 7535-7542, doi: 10.1103/PhysRevB.57.7535

[28] Ungár T., Tichy G., phys stat sol (a). 1999, 171(2), 425-434, doi: 10.1002/(SICI)1521-396X(199902)171:2<425::AID-PSSA425>3.0.CO;2-W

[29] Levine L., Thomson R., Acta Cryst Section A: Foundations of Crystallography.1997, 53(5), 590-602, doi:0.1107/S0108767397005989

[30] Ungar T., Mughrabi H., Rönnpagel D., Acta Metallurgica. 1984, 32(3), 333-342, doi:10.1016/6160(84)90106-8

[31] Fellah L., L'effet de tréfilage et de recuit sur les fils électriques de cuivre, $\mathrm{PhD}$, Mohamed Khider University, Biskra, Algeria,2015,294

[32] Baci L., Boumerzoug Z., Esnouf C., and Bouchear M., Study of Industrial Aluminum Wire after Cold Wire Drawing and Heat Treatments. Metallurgia Italiana, 2008, 2(11), 11-15 [33] Lakhtine I. Métallographie et traitements thermiques des métaux. $3^{\text {ème }}$ Ed., Editions Mir, 1982, pp.55-57.

[34] Zidani M., Messaoudi S., Dendouga F., Baudin T., Derfouf C., Boulagroun A., and Mathon M.-H., MATEC Web of Conferences, 2013, 5(04004), 1-3, doi: $10.1051 /$ matecconf $/ 20130504004$ 
[35] Rollett A., Humphreys F.J., Hatherly M., Rohrer G.S., Recrystallization and Related Annealing Phenomena. $2^{\text {nd }}$ edn. Oxford, UK: Elsevier Pergamon Press, 2004,658

[36] Blatt F.J., Matthiessen's rule. AccessScience: McGraw-Hill Education, 2014

[37] Kovács-csetényi E., Vassel C.R., Kovács I., phys stat sol (a),1971, 7(1), 47-50, doi:10.1002/pssa.2210070103

\section{How to cite this article:}

Fellah L, Boumerzoug Z. Experimental investigation of industrial copper deformed by wire drawing process. J. Fundam. Appl. Sci., 2018, 10(1), 97-112. 